\title{
A PRÁTICA DO BOM PROFESSOR NA FORMAÇÃO INICIAL: UMA ANÁLISE NA PERSPECTIVA DE ACADÊMICOS DO CURSO DE LI- CENCIATURA EM EDUCAÇÃO FÍSICA ${ }^{1}$
}

\author{
Jairo Antônio da Paixão \\ Universidade Federal de Viçosa, Viçosa, Minas Gerais, Brasil \\ Ederley Emanuel Souza \\ Universidade Federal de Viçosa, Viçosa, Minas Gerais, Brasil \\ Jefferson Teixeira de Sousa \\ Universidade Federal de Viçosa, Viçosa, Minas Gerais, Brasil \\ Emanuel Mattos Della Lucia \\ Universidade Federal de Viçosa, Viçosa, Minas Gerais, Brasil
}

\begin{abstract}
Resumo
O estudo analisou a prática pedagógica do professor no ensino superior considerado bom professor na perspectiva de acadêmicos de um curso de licenciatura em Educação Física. A partir de uma pesquisa qualitativa, em que foi utilizado um questionário estruturado na escala Likert de 5 pontos, com 53 acadêmicos que se encontravam matriculados no último ano do curso, foi possível inferir que as boas práticas pedagógicas são ancoradas numa perspectiva crítica de ensino, em que se inserem as dimensões técnica, político-social e humana no processo ensino aprendizagem ao longo da formação inicial dos futuros professores em questão. Em suma, o conceito valorativo de bom professor decorre de fatores percebidos na prática pedagógica do professor ao longo de sua trajetória profissional.
\end{abstract}

Palavras-chave: Prática Pedagógica. Formação de Professor. Educação Física.

\section{THE PRACTICE OF THE GOOD PROFESSOR IN INITIAL TRAINING: AN ANALYSIS IN THE PERSPECTIVE OF ACADEMICS OF THE LICENSEE COURSE IN PHYSICAL EDUCATION}

\begin{abstract}
The study examined the pedagogical practice of the professor considered good teacher from the perspective of academics of a licensee course in Physical Education. From a qualitative research, using a structured questionnaire on the 5-point Likert scale, with 53 students who were enrolled in the last year of the course, it was possible to infer that good pedagogical practices are based in a critical teaching perspective, which includes the technical, politicalsocial and human dimensions in the teaching-learning process throughout the initial training of the future teachers in question. In short, the evaluative concept of good teacher comes from factors perceived in the teacher's pedagogic practice throughout his/her professional career. Keywords: Pedagogical Practice. Teacher's Education. Physical Education.
\end{abstract}

\footnotetext{
${ }^{1} \mathrm{O}$ presente artigo o resultou de uma pesquisa que teve como órgão financiador a Fundação de Amparo à Pesquisa do Estado de Minas Gerais - FAPEMIG, Edital 01/2016 - Demanda Universal, Processo APQ02182-16, no período de agosto de 2016 a julho de 2017.
} 


\section{LA PRÁCTICA DEL BUEN PROFESOR EN LA FORMACIÓN INICIAL: UN ANÁ- LISIS EN LA PERSPECTIVA DE ACADÉMICOS DEL CURSO DE LICENCIATURA EN EDUCACIÓN FÍSICA}

\section{Resumen}

El estudio analizó la práctica pedagógica del profesor de la enseñanza superior considerado buen profesor, desde la perspectiva de académicos de un curso de licenciatura en Educación Física. A partir de una investigación cualitativa en la que se utilizó un cuestionario estructurado en la escala Likert de 5 puntos, con 53 académicos matriculados en el último año del curso, fue posible deducir que las buenas prácticas pedagógicas se anclan en una perspectiva crítica de enseñanza; que se insertan las dimensiones técnica, político-social y humana en el proceso de enseñanza aprendizaje a lo largo de la formación inicial de los futuros profesores en cuestión. En suma, el concepto valorativo de buen profesor deriva de factores percibidos en la práctica pedagógica del profesor a lo largo de su trayectoria profesional. Palabras clave: Práctica Pedagógica. Formación del Profesorado. Educación Física.

\section{Introdução}

Dentre as mais antigas ocupações modernas, a docência tem-se feito presente nos mais diferentes contextos sociais. Conforme assinala Veiga (2006), no sentido etimológico, docência tem suas raízes no latim docere, que significa ensinar, instruir, mostrar, indicar, dar a entender. A docência define-se, pois, como ação educativa que se constitui no processo ensino aprendizagem em espaços educativos formais e não formais, sob determinadas condições históricas. No sentido formal, ainda que a ocupação docente se encontre, nos dias atuais, frente a uma série de dificuldades e desafios, marcada pelo desprestígio social e consequente desvalorização salarial, trata-se de uma ocupação profissional que vem resistindo de forma hercúlea às intempéries das políticas educacionais em nosso país.

Nessa direção, o docente define-se como um profissional em ação e interação com outros, que desenvolve práticas de produção, organização, difusão, apropriação e produção de conhecimentos que se desenvolvem em meios aos processos educativos formais (TARDIF; LESSARD, 2005).

Subvertendo esse entendimento, observa-se que a docência ainda se configura como campo de intervenção profissional em que predomina o entendimento do senso comum de que, para ensinar, basta conhecer o conteúdo a ser trabalhado, sendo o exercício da docência, o verdadeiro lócus para se aprender a ensinar. Trata-se de um entendimento que ainda se faz presente nos diferentes níveis de ensino, inclusive no ensino superior, no qual muitos profissionais que nele atuam também o compreendem como uma verdade plausível (MELLO, 2012; PAIXÃO; CUSTÓDIO; BARROSO, 2016).

Não obstante a isso, por não haver uma exigência legal de preparação para o magistério superior, como ocorre na educação básica, parece coexistir nesse nível de ensino diferentes entendimentos sobre a docência que, por vezes, levam à mal entendidos e situações conflituosas, em que apenas uma parte do corpo docente envolvido diretamente em cursos de formação de professores tem algum tipo de formação didático-pedagógica (MIZUKAMI, 2005-2006).

Conforme estabelece a Lei de Diretrizes e Bases da Educação de 1996 em seu artigo 66, a preparação para o exercício do magistério superior tem sido realizada em nível de pósgraduação (BRASIL, 1996). Por sua vez, a maioria dos professores que atua no ensino superior hoje passou por cursos de mestrado e doutorado vinculados a programas que priorizam a formação para a pesquisa e a especialidade nos temas selecionados para estudo e investigação, 
em detrimento da formação para a docência (PIMENTA; ANASTASIOU, 2014). Essa tendência é reforçada nos processos seletivos relacionados à contratação docente na maioria das instituições de ensino superior no país, que tem priorizado a linha de pesquisa em detrimento da docência e das qualificações pedagógicas do candidato para a função de formador de professores (CUNHA, 2006). Soma-se a essa situação o fato de o reconhecimento desse professor encontrar-se ancorado em atividades de pesquisa relacionadas à pós-graduação, como orientações de dissertações e teses, incluindo as publicações em periódicos de grande impacto nas respectivas áreas do conhecimento.

Sob essa ótica é importante destacar que, infelizmente, ainda se fazem presentes na maioria das instituições de ensino superior o despreparo e o desconhecimento científico por parte dos professores no processo de ensino e de aprendizagem, de acordo com as disciplinas que ministram (PIMENTA; ANASTASIOU, 2014).

Nesse cenário, é comum a prevalência dos processos de reprodução cultural como base da docência, em que se têm professores formadores que fundamentam sua atuação nas experiências como discentes em níveis de escolarização anteriores, tendo como referências seus antigos professores (MELLO, 2012). Tal cenário leva ao entendimento de que se vive uma espécie de naturalização da docência no nível superior de ensino.

A partir de diferentes contextos em que se dá a formação de professores, Hiebert, Gallimorey e Stigler (2002) identificaram uma interdependência marcada pela falta de comunicação, integração e congruência conceitual entre os cursos de formação inicial, as disciplinas pedagógicas e a própria escola, como campo de intervenção profissional. Essa situação, segundo os autores, dificulta o entendimento comum entre os agentes que analisam a formação docente e o significado de bom ensino, bom docente, daqueles que atuam diretamente nos cursos de formação inicial de professores.

Nessa perspectiva, a partir de uma investigação sobre a prática docente, Cunha (2012) define como bons professores aqueles profissionais que apresentam, no ambiente em que se efetiva o processo ensino aprendizagem, a capacidade de explicitarem para os seus alunos o objetivo do que será estudado, localização histórica do conteúdo, estabelecimento de relações do conteúdo em pauta com outras áreas do saber, capacidade de formular questionamentos, de esclarecer conceitos, e explicar claramente. A autora acrescenta que além disso, esses professores mostram que sofrem influências significativas da família com relação a valores, a condição de classe social, e ainda, buscam participar do processo de encaminhamento profissional de seus alunos. Oliveira e Alves (2005) coadunam com essa ideia e acrescem que o bom professor é aquele que estabelece interação com os alunos ancorada na afetividade, pela valorização de sua individualidade e pela dedicação ao trabalho; é aquele que busca se atualizar, tem gosto e compromisso pelo que faz e o faz com dedicação e responsabilidade.

A tudo isso se há de agregar o debate de vertente crítica que tem defendido o caráter multidimensional do processo ensino aprendizagem. Nessa direção, Candau (2012) afirma que a multidimensionalidade no processo de ensino-aprendizagem deve ser analisada de modo que articule consistentemente as dimensões técnica, político-social e humanista. A dimensão técnica se faz presente no processo ensino-aprendizagem como ação intencional, sistemática, que procura organizar as condições que melhor propiciem a aprendizagem, em que se consideram aspectos como objetivos instrucionais, seleção do conteúdo, estratégias de ensino, avaliação, dentre outros. A dimensão político-social leva ao entendimento de que o processo ensino aprendizagem acontece sempre numa cultura específica, ou seja, o professor lida com pessoas concretas que pertencem a posições de classes definidas na organização social em que vivem. Desse modo, a dimensão político-social encontra-se imersa em toda prática pedagógica. E por fim, a dimensão humana faz referência à abordagem humanista que leva a uma perspectiva eminentemente subjetiva, individualista e afetiva presente no processo ensino aprendizagem. A observação equânime pelo professor da multidimensionalidade que perpassa 
o processo ensino aprendizagem é indubitavelmente condição essencial para que boas práticas pedagógicas possam se concretizar nos diferentes ambientes de formação (CANDAU, 2012).

Tendo em vista a necessidade de delimitação de escopo que demandam os processos de investigação, no presente estudo foi considerado o âmbito de formação inicial de professores de Educação Física para atuarem na educação básica da Universidade Federal de Viçosa, MG, o que, a partir deste ponto, será brevemente apresentado.

Para além das disciplinas específicas, a matriz curricular do Curso de Licenciatura em Educação Física da Universidade Federal de Viçosa (UFV) estrutura-se a partir de disciplinas oferecidas por diferentes cursos da instituição como Educação, Biologia, Letras, Nutrição, Bioquímica.

Vale ressaltar que o referido curso passou por uma recente e considerável reestruturação. Dentre as alterações, destaca-se a sua desvinculação da Área Básica de Ingresso (ABI), na qual era facultado ao aluno ingressante escolher a habilitação (Licenciatura ou Bacharelado) após a conclusão do $4^{\circ}$ período, que compreendia as disciplinas do ciclo básico, ou seja, comum às duas habilitações. Além da inserção efetiva da disciplina Prática de Ensino, com carga horária total de 400 horas efetivas, houve o aumento do número de disciplinas de natureza pedagógica. Nesse sentido, a carga horária total do curso passou de 2800 horas para 3200 horas, como determina o Parecer CNE/CP n. 2/2015 (BRASIL, 2015) que trata das Diretrizes Curriculares Nacionais para a Formação Inicial e Continuada dos Profissionais do Magistério da Educação Básica. A implementação dessa reestruturação iniciou-se no primeiro semestre letivo de 2017. Sendo assim, os estudantes têm a oportunidade de estabelecer contato com docentes com formações em outras áreas e, por conseguinte, vivenciar diferentes experiências de aulas, tendo em vista as metodologias de ensino, as estratégias e os recursos educativos, bem como suas avaliações. Isso porque parte-se do entendimento de que o trabalho docente na educação superior, especialmente em cursos de formação inicial de professores, é, sobretudo, uma ação humana, histórica e cultural, que se encontra imbricada numa teia de significados que demandam um envolvimento orgânico entre professor, aluno e os conhecimentos que irão constituir o processo de formação inicial.

A partir das asseverações que envolvem o cenário educacional, a universidade como agência formadora e a escola como campo de intervenção profissional, o presente artigo apresenta uma investigação que teve como eixo norteador os procedimentos adotados pelo bom professor - denominação fundamentada em Cunha (2012) - em sua prática docente ao longo do processo de formação inicial de professores de Educação Física. Nessa perspectiva, este estudo teve como objetivo identificar a prática pedagógica do professor atuante na formação inicial considerado o bom professor na perspectiva de acadêmicos do Curso de Licenciatura em Educação Física da UFV, MG.

\section{Metodologia}

Considerando o fenômeno estudado, foram adotados os procedimentos da pesquisa qualitativa do tipo descritiva (HOLLINSHEAD, 2006). As pesquisas qualitativas caracterizam-se como estudos que se desenvolvem de forma flexível em situações naturais, com dados descritivos detalhados, de modo a focalizar a realidade de forma complexa e contextualizada (LÜDKE; ANDRÉ, 2013). Nesse tipo de pesquisa, é normal que o pesquisador procure entender os fenômenos, segundo a perspectiva dos participantes e, a partir daí, situe sua interpretação. Por assim dizer, a pesquisa descritiva procura analisar fatos e fenômenos, descrevendo detalhadamente como eles se apresentam; é, portanto, uma análise profunda da realidade pesquisada (NEVES, 1996).

Como instrumento de coleta de dados, foi empregado um questionário contendo 13 itens fundamentados na multidimensionalidade do processo ensino aprendizagem (CANDAU, 
2012). Na operacionalização das variáveis contidas nos itens, o questionário encontrava-se estruturado a partir da Escala Likert de 5 pontos, em que o participante podia marcar uma opção (1=discordo plenamente; $2=$ discordo; $3=$ indiferente; $4=$ concordo; $5=$ concordo plenamente) em ordem de importância, tendo em vista sua concepção acerca da temática abordada (FEHRING, 1987). Para fins de discussão dos resultados apresentados nos Quadros 1, 2 e 3, as categorias 1 e 2 foram consideradas negativas, a 3 neutra e as categorias 4 e 5 positivas.

Para os fins específicos de desenvolvimento desta pesquisa, o grupo amostral foi constituído de 53 acadêmicos de ambos os sexos (24 homens e 29 mulheres) que se encontravam matriculados no último ano do curso de Licenciatura em Educação Física da UFV. Na definição do grupo amostral, inicialmente se fez necessário estabelecer contato com o coordenador do curso, e após a explicação acerca da pesquisa e autorização para a sua realização junto aos acadêmicos, foi assinado o termo de autorização. Vale ressaltar que a partir da colaboração do coordenador de curso foi possível levantar as informações sobre a situação dos acadêmicos que se encontravam regularmente matriculados no último ano do curso ou em situação equivalente.

$\mathrm{Na}$ definição dos participantes da pesquisa, foram adotados os seguintes critérios de inclusão: encontrar-se regularmente matriculado no último ano (quinto/sexto período ou em situação equivalente) do Curso de Licenciatura em Educação Física da UFV, concordar em participar da pesquisa e ter assinado as duas vias do Termo de Consentimento Livre e Esclarecido (TCLE). Como critério de exclusão, foram desconsiderados os participantes que não atendiam à situação descrita. A definição na escolha de acadêmicos que se encontravam no último ano do curso se deu em função do maior tempo de convivência destes com os professores que se encontravam à frente das disciplinas do curso, o que confere a esses discentes maior capacidade de discernimento quanto às questões relacionadas aos referidos docentes.

Uma vez definida a amostra, os participantes foram informados acerca dos aspectos relativos à pesquisa e foi solicitada a sua autorização para o desenvolvimento dos procedimentos inerentes à coleta de dados - momento esse em que foi entregue o Termo de Consentimento Livre e Esclarecido, que foi lido e assinado pelos mesmos. Como procedimento prévio à aplicação dos questionários, foram agendados individualmente com cada participante data, horário e local, em virtude das disponibilidades dos mesmos. A coleta de dados ocorreu no período de 09 de maio a 29 de junho de 2017.

Os resultados obtidos nesta investigação encontram-se organizados na sessão Resultados e Discussão em três quadros, a partir das seguintes categorias de análise: Quadro 1 - dimensão técnica, Quadro 2 - dimensão político-social e, por fỉm, Quadro 3 - dimensão humanista.

Na execução deste estudo, foram consideradas as diretrizes regulamentadas pela Resolução $n^{\circ}$ 466/12 da CONEP. O projeto de pesquisa obteve aprovação pelo Comitê de Ética em Pesquisa com seres humanos da UFV, Ofício CEP n ${ }^{\circ} 1.636 .551$ de 14 de julho de 2016.

\section{Resultados e discussão}

A discussão dos resultados obtidos desenvolveu-se através da triangulação entre os dados dos questionários aplicados aos acadêmicos do curso de licenciatura em Educação Física; a bibliografia utilizada, que vinha ao encontro da temática abordada; e, também, as posições assumidas pelos autores da investigação em relação ao tema. Dessa forma, foram possíveis a compreensão e discussão das categorias de análise, que se encontram organizadas em três momentos: dimensão técnica, dimensão político-social e dimensão humanista, tendo em vista a multidimensionalidade do processo ensino aprendizagem (CANDAU, 2012).

\section{Dimensão técnica}


Quadro 1 - Dimensão Técnica

\begin{tabular}{|c|c|c|c|c|c|}
\hline \multirow[b]{2}{*}{ Variáveis consideradas } & \multicolumn{5}{|c|}{ Escala de Likert } \\
\hline & 1 & 2 & 3 & 4 & 5 \\
\hline $\begin{array}{l}\text { Diversificava as estratégias, recursos educativos e/ou } \\
\text { audiovisuais nas aulas. }\end{array}$ & - & 2 & 12 & 24 & 15 \\
\hline $\begin{array}{l}\text { Demonstrou conhecimento/domínio sobre } \text { o conteúdo } \\
\text { trabalhado na disciplina. }\end{array}$ & - & - & - & 2 & 51 \\
\hline $\begin{array}{l}\text { Demonstrou capacidade de formular questionamentos, } \\
\text { esclarecer conceitos e explicar claramente o conteúdo. }\end{array}$ & - & - & - & 8 & 45 \\
\hline $\begin{array}{l}\text { Adotava procedimentos para esclarecer dúvidas e/ou } \\
\text { dificuldades dos alunos durante as aulas. }\end{array}$ & - & 1 & 4 & 24 & 24 \\
\hline $\begin{array}{l}\text { Buscava relacionar o conteúdo trabalhado com outras áreas } \\
\text { do saber. }\end{array}$ & - & 2 & 11 & 23 & 17 \\
\hline $\begin{array}{l}\text { Mantinha coerência entre o conteúdo trabalhado e a forma } \\
\text { de avaliação adotada. }\end{array}$ & - & - & - & 16 & 37 \\
\hline
\end{tabular}

Nota: $\mathbf{1}=$ Nunca $; \mathbf{2}=$ Poucas vezes; $\mathbf{3}=$ Ás vezes; $\mathbf{4}=$ Muitas vezes; $\mathbf{5}=$ Sempre

Fonte: Elaborado pelos autores, 2018.

Como mostra o Quadro 1, dentre as variáveis pertencentes à dimensão técnica e que, por sua vez, perpassam a prática pedagógica dos professores selecionados pelos participantes da pesquisa como bons professores, foram destacados o conhecimento e/ou domínio sobre o conteúdo trabalhado (100\%) e a capacidade de formular questionamentos, explicar com clareza e tirar dúvidas sobre o conteúdo (100\%). Na sequência, a capacidade de diversificar as estratégias e recursos educativos no processo de ensino-aprendizagem (74\%) e adoção de procedimentos para sanar dúvidas e dificuldades pelos alunos (91\%) foram apontadas como variáveis que, na opinião dos participantes, caracterizam o bom professor. Um bom professor deve ter práticas de trabalho diversificadas, buscar coisas novas que chamem a atenção do aluno para o conteúdo, e usar bem o tempo em sala de aula, o que é primordial. Para que isso se efetive, o professor deve ter um bom planejamento, organização e interesse. Somado a isso, é necessário conhecer e ter domínio do conteúdo. O modo de atendimento aos estudantes deve ser de maneira igualitária, seja individualmente ou em grupo.

Ainda foram ressaltadas, na perspectiva dos acadêmicos a coerência entre o conteúdo trabalhado com o modelo de avaliação adotada (100\%) e estabelecimento da relação do conteúdo trabalhado com outras áreas do saber (75\%) pelos professores. Esses dados chamam a atenção quando analisados a partir de estudo desenvolvido por Pimenta (1999), no qual afirma se tratar de procedimentos essenciais para formação de futuros professores, pelo fato de sinalizarem elementos facilitadores para o trabalho interdisciplinar, contextual e abrangente nos espaços em que se efetivam processos de ensino aprendizagem.

A dimensão técnica se faz presente no processo de ensino-aprendizagem na ambiência da educação formal como ação intencional, sistemática adotada pelo professor (CANDAU, 2012). Trata-se da dimensão concreta e objetiva do processo ensino aprendizagem, razão pela qual essa dimensão foi exaltada. Sob a influência da tendência tradicional num contexto marcado pela predominância da didática instrumental, a dimensão técnica não somente teve primazia sobre as demais, mas era concebida como eixo norteador das boas práticas docentes. Cumpre destacar que as variáveis que versam a dimensão técnica, consideradas no presente estudo, voltam-se para uma perspectiva crítica de ensino. Isso por entender que o modelo que 
atendia às demandas de uma sociedade em outros tempos mostra-se, hoje, incapaz para confrontar os novos desafios da sociedade contemporânea. De acordo com Candau (2012, p. 112), na maioria das vezes, "[...] a deficiência da prática educativa encontra-se na metodologia e no modo de fazer a educação. [...]". Assim, uma das maiores dificuldades encontradas pelo professor é desenvolver efetivamente a sua prática pedagógica embasada numa perspectiva crítica de ensino. Ademais, em espaços como as instituições de ensino superior, onde comumente se efetiva a formação inicial de professores, o ensino deve servir para uma reconceitualização desse ensino, que não deve ser focado pelo prisma de sua importância, mas pelo ponto de vista que busca a complementaridade das ações a serem realizadas por parte dos docentes e dos estudantes.

\section{Dimensão político-social}

Quadro 2 - Dimensão político-social

\begin{tabular}{|c|c|c|c|c|c|}
\hline \multirow[b]{2}{*}{ Variáveis consideradas } & \multicolumn{5}{|c|}{ Escala de Likert } \\
\hline & 1 & 2 & 3 & 4 & 5 \\
\hline $\begin{array}{l}\text { Demonstrou significativa relação entre o conteúdo } \\
\text { trabalhado e a sua aplicação no âmbito profissional. }\end{array}$ & - & - & 4 & 13 & 36 \\
\hline $\begin{array}{l}\text { Se mostrou atualizado, tem gosto e compromisso pelo que } \\
\text { faz e o faz com dedicação e responsabilidade. }\end{array}$ & - & - & 1 & 12 & 40 \\
\hline $\begin{array}{l}\text { Abordava aspectos relacionados a diferenças presentes na } \\
\text { sociedade e possíveis implicações na atuação profissional. }\end{array}$ & - & 1 & 9 & 16 & 27 \\
\hline $\begin{array}{l}\text { Buscava explicitar o objetivo do conteúdo trabalhado para o } \\
\text { seu processo de formação inicial. }\end{array}$ & - & 1 & 1 & 15 & 36 \\
\hline
\end{tabular}

Nota: $\mathbf{1}=$ Nunca; $\mathbf{2}=$ Poucas vezes; $\mathbf{3}=$ Ás vezes; $\mathbf{4}=$ Muitas vezes; $\mathbf{5}=$ Sempre

Fonte: Elaborado pelos autores, 2018.

Os resultados apresentados no Quadro 2 demonstram que, no tocante às variáveis que integralizam a dimensão político-social consideradas no presente estudo, $81 \%$ dos docentes atuantes no processo de formação inicial do curso de licenciatura em Educação Física da UFV abordavam aspectos sociais e suas possíveis implicações na atuação profissional. Desse modo, nota-se que, na perspectiva dos estudantes, a maioria dos professores (98\%) buscava se atualizar e realizar suas atividades com empenho e dedicação, bem como explicitava a interface dos conteúdos trabalhados com as realidades que perpassam o âmbito profissional, o que, por sua vez, pode influenciar de forma significativa na formação de futuros professores, visto que estes estarão inseridos em um contexto diretamente influenciado por manifestações culturais, políticas e sociais, proporcionando um preparo para lidar com essas situações. Geralmente quando o professor consegue contextualizar conteúdo com aspectos da realidade, sobre o cotidiano, são aumentadas as possibilidades de êxito a partir da aprendizagem significativa. Sobre esses aspectos Oliveira e Alves (2005) afirmam que o bom professor é aquele que busca se atualizar, tem gosto e compromisso pelo que faz e o faz com dedicação e responsabilidade.

As variáveis que circunscrevem a dimensão político-social, as quais, indubitavelmente, perpassam o processo de ensino aprendizagem, levam ao entendimento de que as ações humanas não são neutras ou isentas de posições de classe. O fazer e o pensar, o conteúdo e sua forma de ensinar, assim como o que é priorizado e o que é relegado à margem na formação de professores são determinados socialmente, num processo mediatizado pela relação que 
se estabelece num dado momento histórico entre educação e sociedade. Na visão de Candau (2012, p. 116), “[...] a metodologia contém em si mesma uma função política que corresponde aos objetivos que se pretende alcançar, a serviço de que, quem e de qual sociedade". A metodologia é uma ferramenta de fundamental importância para o educador, quando se tem uma metodologia renomada tudo ocorre bem, por isso Candau (2012) assevera que a busca por superação e melhorias no processo de formação tem sido norteada pelo compromisso com uma pedagogia voltada à transformação social e à construção de práticas pedagógicas adequadas à diversidade de alunos presentes nas salas de aulas.

\section{Dimensão humanista}

Quadro 3 - Dimensão Humanista

\begin{tabular}{l|l|l|l|l|c}
\hline \multicolumn{1}{c|}{ Variáveis consideradas } & \multicolumn{5}{l}{ Escala de Likert } \\
\cline { 2 - 7 } & $\mathbf{1}$ & $\mathbf{2}$ & $\mathbf{3}$ & $\mathbf{4}$ & $\mathbf{5}$ \\
\hline $\begin{array}{l}\text { A relação do (a) professor (a) com a turma ao longo do } \\
\text { semestre influenciou de forma significativa no processo de } \\
\text { ensino-aprendizagem. }\end{array}$ & - & 2 & 19 & 32 \\
\hline $\begin{array}{l}\text { Demonstrou cordialidade, respeito e consideração à } \\
\text { diversidade dos alunos no decorrer da disciplina. }\end{array}$ & - & - & 3 & 14 & 36 \\
\hline
\end{tabular}

Nota: $\mathbf{1}=$ Nunca; $\mathbf{2}=$ Poucas vezes; $\mathbf{3}=$ Ás vezes; $\mathbf{4}=$ Muitas vezes; $\mathbf{5}=$ Sempre

Fonte: Elaborado pelos autores, 2018.

O Quadro 3 apresenta duas variáveis que consubstanciam de forma significativa uma diversidade de aspectos atinentes à dimensão humanista presente no processo ensino aprendizagem. Trata-se de uma dimensão, conforme afirma Candau (2012), que se faz presente nos diferentes segmentos da educação formal.

Os resultados indicam que a quase totalidade dos professores estabeleceram uma boa relação com os estudantes, marcada pela cordialidade, respeito no decorrer do período letivo, o que, segundo Candau (2012), influencia positivamente no processo de ensinoaprendizagem. A prática docente exige que o professor esteja disposto às relações afetivas com os educandos e com a sua própria prática educativa. A afetividade não diminui a seriedade docente; na verdade, o que não pode ocorrer é que essas relações afetivas interfiram no cumprimento ético do dever de professor no exercício de sua autoridade. O professor deve ser flexível, saber seu posicionamento como professor e como educador. Na visão de Oliveira e Alves (2005), dentre as características do bom professor, inclui-se a interatividade com os alunos, marcada pela afetividade, pela valorização de sua individualidade e pela dedicação ao trabalho.

\section{Conclusão}

Diante das constatações obtidas por meio desta investigação, é possível afirmar que a análise realizada, que teve como eixo norteador a multidimensionalidade no processo ensino aprendizagem e o conceito valorativo de bom professor na perspectiva de acadêmicos do Curso de Licenciatura em Educação Física da UFV, forneceu elementos que despertam para uma reflexão sistemática sobre formação de professores.

Como evidenciado, o processo ensino aprendizagem de um dado conteúdo é perpassado por diferentes dimensões (técnica, político-social e humanista) que, irremediavelmente, dependendo da maneira como o professor as percebe em sua prática pedagógica cotidiana, incidirão em um tipo de formação. Os resultados obtidos mostraram consonância nos aspectos 
relativos à multidimensionalidade na prática pedagógica dos professores considerados pelos acadêmicos, o que leva a pressupor se tratar de uma característica comum entre esses professores que, por sua vez, podem ter contribuído para situações exitosas vivenciadas pelos estudantes participantes deste estudo.

Nesta perspectiva, as boas práticas desenvolvidas pelos professores podem ser compreendidas tendo em vista ações como a interdisciplinaridade, a manutenção da prática de intervenção atualizada e em constante interface com aspectos políticos e sociais, somadas ao gosto, ao compromisso, à dedicação e à responsabilidade mediatizadas por boas relações interpessoais no ambiente de aprendizagem.

Sobretudo, tem-se o entendimento de que a multidimensionalidade, que se faz presente no processo ensino aprendizagem efetivado a partir do conceito valorativo do bom professor no curso de formação inicial, favorece o desenvolvimento de conhecimentos, habilidades, atitudes e valores nos futuros professores, elementos esses que lhes possibilitarão irem construindo e transformarem seus saberes-fazeres docentes a partir das necessidades e desafios que o ensino como prática social concreta impõe ao professor ao longo de sua trajetória docente. Para tanto, entende-se que a formação inicial de professores deve ser efetivada num contexto multidimensional, não perdendo de vista binômios como educação-sociedade, educação-política, educação-cultura e demais campos sociais que podem abranger o ser humano.

Ao enfatizar características do bom professor num contexto que leva em consideração a multidimensionalidade do processo ensino aprendizagem numa perspectiva crítica de ensino nos cursos de formação inicial de professores, está se admitindo a complexidade da docência e a dificuldade que envolve o ato de preparar novas gerações de docentes para atuar num contexto incerto e de ininterruptas mudanças.

E, por fim, a análise realizada na presente investigação revelou que o conceito valorativo de bom professor decorre de fatores percebidos pelos acadêmicos na prática docente que certamente vão se agregando num ininterrupto processo ao longo de sua trajetória profissional num dado segmento e contexto educacional.

\section{Referências}

BRASIL. Conselho Nacional de Educação. Lei de Diretrizes e Bases da Educação Nacional: lei ${ }^{\circ}$ 9.394, de 20/12/1996, estabelece as diretrizes e bases da educação nacional. Diário Oficial da União, Brasília, DF, 23 dez. Seção I, 1996.

BRASIL. Conselho Nacional de Educação. Resolução $\mathbf{n}^{\circ}$ 2, de $\mathbf{1}^{\mathbf{0}}$ de julho de 2015. Define as Diretrizes Curriculares Nacionais para a formação inicial em nível superior (cursos de licenciatura, cursos de formação pedagógica para graduados e cursos de segunda licenciatura) e para a formação continuada. Diário Oficial da União, Brasília, DF, 20 dez., 2015.

CANDAU, V. M. A didática em questão. 33. ed. Petrópolis: Vozes, 2012.

CUNHA, M. I. Docência na universidade, cultura e avaliação institucional: saberes silenciados em questão. Revista Brasileira de Educação, v. 11 n. 32, p. 258-371, maio/ago. 2006. Disponível em: 〈http://www.scielo.br/pdf/rbedu/v11n32/a05v11n32.pdf>. Acesso em: 07 out. 2016.

O bom professor e sua prática. 24. ed. Campinas: Papirus, 2012. 
FEHRING, R. J. Methods to validate nursing diagnoses. Heart Lung, England, v. 16, n. 6, p. 625-629, nov. 1987.

HIEBERT, J.; GALLIMORE, R.; STIGLER, J. W.; A knowledge base for the teaching profession: what would it look like and how can we get one? Educational Researcher, v. 31, n. 5, p. 3-15, jun. 2002.

HOLLINSHEAD, K. The shift to constructivism in social inquiry: some pointers for tourism studies. Tourism Recreation Research, v. 31, n. 2, p. 43-58, 2006.

LÜDKE, M.; ANDRÉ, M. E. D. A. Pesquisa em educação: abordagens qualitativas. 2. ed. São Paulo: EPU, 2013.

MELLO, I. C. A docência no ensino superior: descrição e análise de um percurso formativo. In: KASSAR, M. de C. M.; SILVA, F. de C. T. (Org.). Educação e pesquisa no CentroOeste: políticas, práticas e fontes da/para a formação do educador. Campo Grande: UFMS, 2012.

MIZUKAMI, M. G. N. Aprendizagem da docência: professores formadores. Revista ECurriculum, São Paulo, v. 1, n. 1, dez./jul. 2005-2006. Disponível em: <http://www.pucsp.br/ecurriculum>. Acesso em: 07 outubro 2016.

NEVES, J. L. Pesquisa qualitativa - características, uso e possibilidades. Cadernos de Pesquisa em administração, São Paulo, v. 1, n. 3, 2º sem. 1996.

OLIVEIRA, C. B. E.; ALVES, P. B.; Ensino fundamental: papel do professor, motivação e estimulação no contexto escolar. Paidéia, São Paulo, v. 15, n. 31, p. 227-238, ago. 2005.

PAIXÃO, J. A.; CUSTÓDIO, G. C. C.; BARROSO, Y. W. S. O processo de aprendizagem do professor de educação física atuante em academias de ginástica no início de carreira. Pensar a Prática, Goiânia, v. 19, n. 2, p. 286-299, abr./jun. 2016.

PIMENTA, S. G. Formação de professores: identidade e saberes da docência. In: PIMENTA, S. G. (Org.). Saberes pedagógicos e atividade docente. São Paulo: Cortez Editora, 1999. p. 15-34.

PIMENTA, S. G.; ANASTASIOU, L. G. C. Docência no Ensino Superior. 5. ed. São Paulo: Cortez, 2014.

TARDIF, M.; LESSARD, C. O trabalho docente: elementos para uma teoria da docência como profissão de interações humanas. Petrópolis: Vozes, 2005.

VEIGA, I. P. A. Docência Universitária na Educação Superior. In: VI Simpósio promovido pelo Instituto de Estudos e Pesquisas Educacionais "Anísio Teixeira" (INEP). Brasília. Dezembro, 2005. Disponível em: $</$ www.naeg.prg.usp.br/gap/secoes/seminario/docencia_universitaria_na_educacao_superior. pdf $>$. Acesso em: 05 abril 2017. 
Revisado em: 01/03/2018

Aprovado em: 23/08/2018

Endereço para correspondência:

jairopaixao2004@yahoo.com.br

Jairo Antônio Paixão

Universidade Federal de Viçosa - Departamento de Educação

Programa de Pós-Graduação em Educação

Avenida Purdue, $\mathrm{s} / \mathrm{n}^{\circ}$

Campus Universitário

36570.900 - Viçosa - MG - BR 